\title{
Digital Nudges for Screen Time Reduction: A Randomized Control Trial with Performance and Wellbeing Outcomes
}

\author{
Laura Zimmermann (School of Human Sciences \& Technology, IE University) \\ Michael Sobolev (Cornell Tech, Cornell University)
}

Date: Dec 30, 2020

\begin{abstract}
Address correspondence to laura.zimmermann@ie.edu or michael.sobolev@cornell.edu
\end{abstract}
\begin{abstract}
Many people want to reduce their smartphone usage to increase productivity and well-being, but fail to accomplish this goal. We conduct a randomized control trial with a student population $(\mathrm{N}=112)$ over three weeks to test the effectiveness of two widely available digital nudges for screen time reduction. Along with a tracking-only control condition, a passive digital nudge (i.e., grayscale mode) was compared to an active digital nudge (i.e., time limits). The passive nudge led to an immediate, significant reduction of objectively measured screen time compared to the control condition. Conversely, the active nudge led to a smaller and gradual screen time reduction. Those in the control condition, who simply tracked their usage, did not lower their screen time. As opposed to the popular belief that reducing screen time is beneficial, we found no immediate causal effects of reducing screen time on subjective well-being and academic performance.
\end{abstract}

Keywords: Screen time, Digital addiction, Digital nudge, Cyberpsychology, Distraction, Smartphone

\section{Statement of Relevance}

Despite the huge advantages of smartphones, a significant proportion of people believe they are over-using their phone and would like to change their mobile habits. As a solution, screen time applications were recently launched by the biggest technology companies (e.g., Apple) to empower people to change their smartphone usage and to increase digital wellbeing. In this study, we experimentally test the effectiveness of two smartphone features for reducing screen time: grayscale mode and time limits. These features are available on nearly any smartphone and are designed to nudge people to spend less time on the phone, for example with time limits for 'addictive' social media apps. We confirm the effectiveness of these digital nudges for supporting users in their endeavour to reduce screen time. Conversely to the typically expected benefits, we find no improvements of well-being or academic performance due to reduced smartphone usage. 


\section{Introduction: The Smartphone Dilemma}

Since their inception less than 15 years ago, smartphones had an unparalleled success story. For many of the approximately 3.5 billion smartphone users worldwide (Statista, 2020), the phone is an ever-present companion in their life. On average, users spend over 3.5 hours daily looking at their smartphone (GlobalWeblndex, 2020) adding up to 53 days per year. The fundamental change in mobile technology has impacted our lives not only positively. Recently, ample media discussion has raised concern about the increasing "addictiveness" of mobile technology.

This is supported by research highlighting negative links between smartphone usage and performance at work (Lanaj et al., 2014) and university (Felisoni \& Godoi, 2018), emotional health (Lee et al., 2014), sleep patterns (Thomée et al., 2011) as well as cognitive capacity (Ward et al., 2017). Despite recent controversy regarding the magnitude (Bjerre-Nielsen et al., 2020) and causality of such negative relationships (as in the case of screen time and wellbeing in adolescents; Orben \& Przybylski (2019a)), many people see it as an important self-improvement goal to reduce their screen time. In fact, a significant proportion describe themselves as smartphone "over-users" (Deloitte, 2019).

A habitual, automatic and impulsive behavior such as mobile usage (Billieux et al., 2008; Lyngs et al., 2019; Sobolev et al., 2020; Wen et al., 2020) is difficult to change. Apart from pragmatic purposes, smartphones convey deep-rooted emotional benefits that are hard to replace. Melumad and Pham (2020) show that smartphones are essentially "adult pacifiers" enhancing psychological comfort in stressful times. Smartphones, particularly their social media apps, help people regain a sense of community and belonging (David \& Roberts, 2017). Thus, it is not surprising that it is hard for people to reduce their mobile usage. The extreme notion of "digital addiction", however, implies that behavior change is almost impossible with self-imposed techniques. Labelling smartphone usage as "addictive", rather than problematic or maladaptive, seems to be unjustified based on literature at this point (Panova \& Carbonell, 2018).

Our research answers the question of whether two digital nudges (Okeke, Sobolev, \& Estrin, 2018), that are readily available on almost any smartphone, can be effective tools to lower mobile usage. Theoretically, we distinguish between an active (i.e., time limits) and a passive (i.e., grayscale mode) nudge and evaluate their impact on objectively measured screen time. Finally, we investigate the causal effect of reducing screen time on subjective well-being and academic performance in the form of grade point average (GPA).

\section{Previous research on solutions for reducing screen time}

Both low-tech and high-tech solutions for screen time reduction can be effective. Allcott et al. (2020) incentivized individuals with monetary rewards to deactivate Facebook for four weeks leading to a $90 \%$ compliance rate. The immediate decrease in online activity was accompanied by an increase in wellbeing. Their intervention also led to a persistent reduction in Facebook use after the experiment. However, monetary incentives for screen time reduction are often not feasible or scalable. Further, they 
can "crowd out" intrinsic motivation and be counterproductive for long-term habit formation (Gneezy et al., 2011).

Digital solutions for screen time reduction vary along an active-passive continuum depending on the required engagement. Active digital nudges require users to proactively engage in behavior change strategies, for example by using planning prompts or by setting time limits. Apps with time limits are the most common nudges to enhance digital self-control (Lyngs et al., 2019). They can reduce self-interruptions and stress (Kim et al., 2017) as well as smartphone usage (Ko et al., 2015). At the opposite end of the continuum lie passive digital nudges including reminders and feedback messages (Hiniker et al., 2016), screen changes or vibrations (Okeke, Sobolev, Dell, et al., 2018). Passive nudges do not require specific actions from users and do not limit the ability to use the phone (as opposed to time limits). But, they provide more support than just usage information to nudge individuals to reduce screen time. Passive digital nudging can be achieved, for example, by incorporating design frictions in the usage process which introduce difficulty in the technology interaction. This can disrupt automatic behavior and stimulate more mindful interaction with the phone (Cox et al., 2016). As a prime example, Okeke et al. (2018) developed a mobile app that digitally nudges individuals when exceeding a daily Facebook limit via subtle, repeating phone vibrations. This passive digital nudge led to a $20 \%$ decrease in Facebook use.

In most cases, the apps and interventions used previously were specifically developed for research purposes limiting their scalability and impact. It is extremely hard to convince people to download and use apps in natural settings outside the lab (Murnane et al., 2015). We use a scalable approach by leveraging mobile features that are readily available on most phones. Faced with the reckoning of ever increasing "mobile addiction", tech giant Apple released a time management application (Screen Time) as part of its operating system. The Screen Time app is one of the most accessible solutions to mobile reduction since it is almost ubiquitously available on any iPhone. Using the active nudge approach, users can self-commit to abstain from their phone at specific times or after reaching time limits .

A widely accessible passive nudge is 'grayscale mode' (i.e., turning ones' phone screen to black and white). Grayscale mode was originally developed for colorblind people but recently it has been hailed as an effective design friction to curb smartphone usage. It is a passive nudge since it steers users towards reducing usage by making the experience less engaging, while preserving all functionality.

\section{The current research}

We experimentally investigate the effect of two digital nudges compared to a control group for screen time reduction in a field study. We leverage the capabilities of Apple's Screen Time app to alter the choice architecture of mobile consumption using a passive and an active digital nudge (as illustrated in Figure 1). Our randomized control trial includes three conditions: (1) Control: self-tracking of phone usage; (2) Passive nudge: changing the color of the screen (i.e., grayscale mode) to be less engaging; (3) Active nudge: self-committing to restrictive time limits on phone and app usage. 

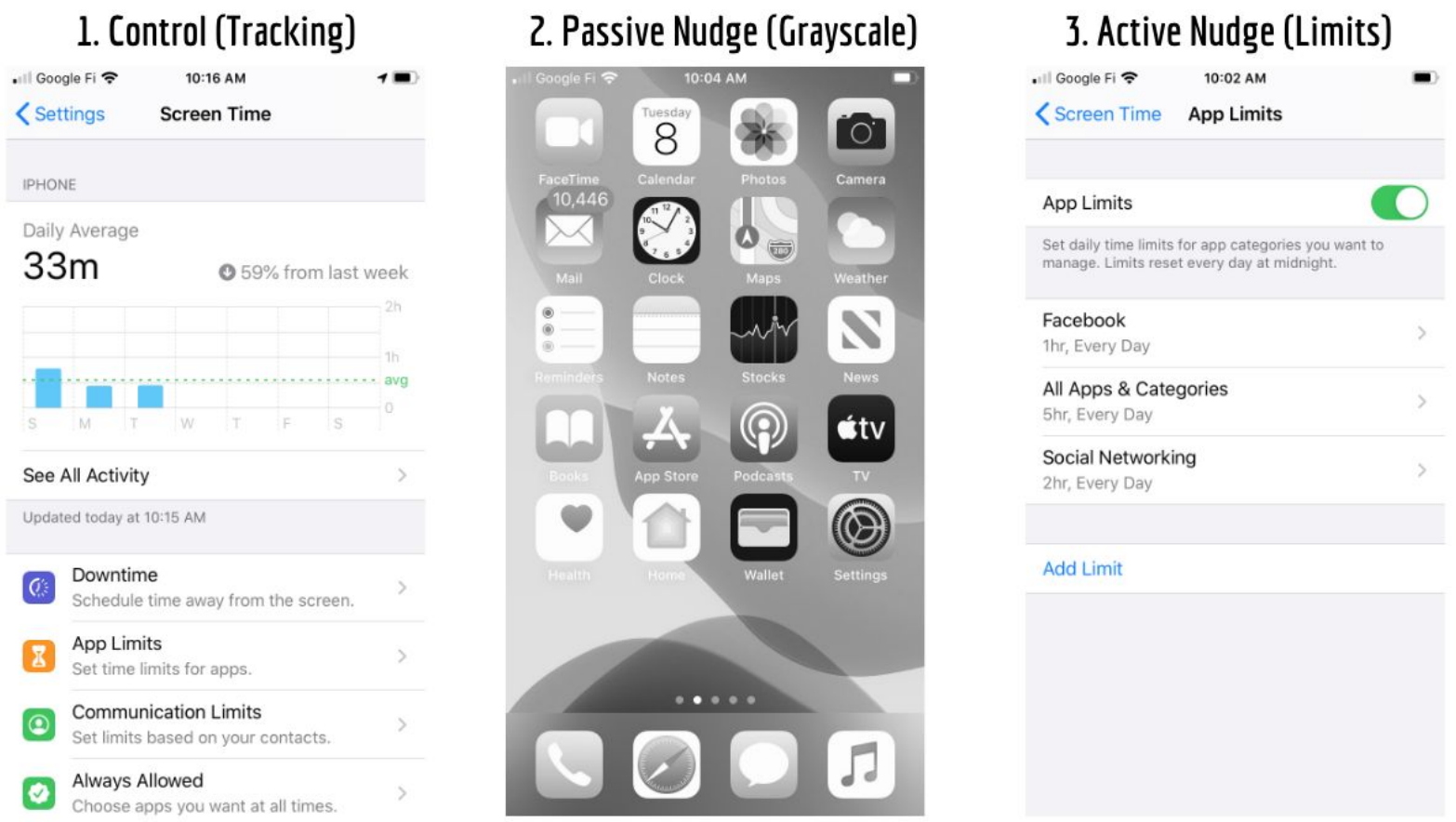

Figure 1. Experimental conditions in the study.

In line with the nudge approach, these changes to the digital choice architecture were suggested but not enforced (Thaler \& Sunstein, 2008). We test whether these digital nudges are effective in decreasing screen time compared to the control condition and investigate the causal impact of a reduction on academic performance and wellbeing.

We contribute to the previous literature in the following ways. First, we measure mobile screen time objectively using a novel methodological approach (i.e., screenshots of screen time apps). Second, employing an RCT, we systematically test the effectiveness of interventions which are available to most smartphone users free of cost. Third, we investigate grayscale mode as a passive nudge and compare it to the established active nudge of time limits. Finally, we contribute to the understanding of the causal relationship between screen time, academic performance and well-being.

\section{Method}

\section{Participants}

The study was run as part of a workshop at a large university with an international body of students. The workshop was provided for different postgraduate programs and introduced students to the science of attention and the role of distractions in the workplace. As part of the workshop, students completed a 'smartphone project' which entailed tracking their phone usage with a screen time app (see description below) over a period of several weeks. This smartphone project constituted our intervention. 
Our sample size was based on the availability of participants. We enrolled the maximum number of participants who consented $(\mathrm{N}=353)$ out of the total number of workshop participants $(\mathrm{N}=395)$. To reduce unnecessary variance, we only focused on iPhone users (the majority of our sample). We aimed to recruit enough participants so that each experimental condition would include at least $\mathrm{N}=50$ participants. Previous research indicated a high effect size (Cohen's d between 0.4 and 0.5 ) for screen time reduction interventions. Under this assumption, assuming a sample of at least 40 participants per condition, our study should be able to detect an effect in a one-way ANOVA with at least $97 \%$ power.

The final sample consisted of 112 participants (Mage=26 years; $77 \%$ female). We excluded participants who did not submit viable screen time data, who did not complete a post-treatment survey or did not correctly answer check-up questions about their assigned condition (see Figure S1 for details).

\section{Description of Screen Time App}

Apple's Screen Time app, now a core feature of iOS, provides a graphical overview of daily as well as weekly total screen time. Screen time is also organized in different categories (e.g., social networking, productivity, gaming, reading \& reference). In addition, users can see their most used apps, their number of pickups and notifications. These features allowed our control condition to self-monitor their mobile behavior. For our active nudge condition, two time management features in the app were used: 1) 'Downtime' allows people to schedule time away from the screen during which only phone calls and certain apps are be available; 2) 'App Limits' allows users to set daily time limits for certain apps or app categories such as social networking. Limits are reset every day at midnight. If a person reaches their limit, the app is blocked and a notification is provided. Users can extend or remove their self-set limits, meaning that the time limits are not strictly enforced.

\section{Experimental Design}

Each participant was randomly assigned to one of three conditions: 1) control condition ( $n=39), 2$ ) passive nudge condition (grayscale, $n=40$ ), or 3 ) active nudge condition (time limits, $n=33$ ). All conditions included basic instructions to use Apple's Screen Time feature on iPhone devices.

In the control condition, participants were instructed to use Screen Time to track their phone usage during the study period (Figure 1, left). They were instructed to simply observe their phone usage without any additional suggestions. In the passive nudge condition, participants were instructed to track their usage and also change their phone to grayscale mode during the study period (Figure 1, middle). Specifically, they were instructed to switch their phone display from color to grayscale mode (i.e. black and white screen). In the active nudge condition, participants were instructed to track their usage and also set themselves time limits for their phone usage during the study period (Figure 1, right). They were instructed to activate the 'Downtime' feature to schedule time away from the screen during which they wouldn't use the phone. In addition, they were instructed to activate the 'App Limits' feature to set time limits for different apps. Our experimental design was pre-registered (aspredicted.org/9ss3t.pdf) and received approval from the university review board.

Participants completed a baseline survey (T1) before the intervention as well as a post-treatment survey (T2). The instructions for each condition, supplementary materials and survey items are available at OSF 
(osf.io/k9bdf). There were no significant differences at baseline between the different conditions on key measures, including smartphone dependence, ability to reduce mobile usage and self-reported mobile usage (i.e., screen time, number of unlocks, number of notifications). See Table S1 for a complete overview of the sample characteristics across conditions.

\section{Procedure and Measures}

\section{T1 Survey}

Participants received an online survey before the workshop (and smartphone project) with questions about their smartphone usage and subjective wellbeing, embedded in other teaching-related items. We describe the key measures next.

First, participants estimated their typical smartphone screen time per day (in hours and minutes), their typical number of unlocks, and notifications per day. We also asked how much participants would be able to reduce their screen time (scale: $0-100 \%$ reduction). While participants were unaware of the mobile project at this point, we elicited their beliefs about how effective they thought three different techniques were for reducing screen time (Efficacy expectations: "Looking at detailed information about your individual smartphone usage", "Setting yourself time limits for different apps", "Turning your smartphone to grayscale mode", $0=$ not at all effective, 100=very effective). Next, we elicited participants' subjective wellbeing; specifically, their life satisfaction, sleep quality, stress level and happiness. This was followed by an eleven-item smartphone dependence scale from Ward et al. (2017). Finally, participants answered questions regarding demographics (age, gender), use of screen time apps (current usage, which app?) and provided informed consent.

\section{Screen Time}

Previous research indicates that subjective screen time estimates only weakly correspond to objectively measured screen time (Andrews et al., 2015; Boase \& Ling, 2013; Kaye et al., 2020). Thus, to collect objective screen time data, participants were instructed to take screenshots of their average smartphone usage ('last 7 days') as provided in the Screen Time app, after every seven days from when they received the instructions. Participants submitted these screenshots online, which were then coded manually. The average daily screen time in minutes obtained from the screenshots constitutes our main dependent variable.

\section{T2 Survey}

After the final workshop session (and the end of the smartphone project), participants received a second online survey with questions regarding the project, compliance checks, subjective wellbeing and two attention measures. We describe the key measures next.

The survey was adapted to the experimental conditions. Participants in the passive nudge condition indicated which percentage of time during the project they had activated grayscale mode $(0=$ not at all, $100=$ all the time), and whether grayscale mode had helped them to reduce screen time $(0=$ definitely not, $100=$ definitely yes). Participants in the active nudge condition were probed which goal-setting 
features they had activated in the app, and to describe which limits they had set themselves. They were further asked how frequently they had broken their own time limits ( $0=$ almost never, 100=almost every day), and whether these had helped them to reduce screen time ( $0=$ definitely not, $100=$ definitely yes).

All participants estimated the percentage of productive mobile time during the project (0\%-100\%) and their enjoyment of social media (e.g., Instagram, Facebook, YouTube) on their phone during the project ( $0=$ not at all, 100=very much). All participants were asked whether using the Screen Time app had helped them to reduce their mobile usage ( $0=$ definitely not, $100=$ definitely yes), and whether they had felt committed to lowering their usage $(0=$ not at all, $100=$ very much). Next, all participants completed the same wellbeing questions as previously. Finally, to measure attention, participants completed three items from the Cognitive Reflection Test (Frederick, 2005) and an attention filter item ('Select strongly disagree') embedded in the Ten Item Personality Inventory (Gosling et al., 2003).

\section{Academic Performance}

To measure academic performance, we collected GPA for all courses from the university administration with consent from participants. Since this was the first year of studying for our participants, we were not able to obtain pre-treatment GPAs.

\section{Results}

We report the effect of the experimental condition on screen time, subjective well-being, and academic performance. We provide descriptive results on the feasibility and acceptability of the Screen Time app and the digital nudges. We additionally describe exploratory finding on other outcomes.

\section{Efficacy Expectations T1}

There were no differences in efficacy expectations across the conditions (all $p s=n s$ ) before the project. However, participants had different efficacy expectations for the three techniques $(F(2,220)=18.87$, $p<.001)$. Surprisingly, grayscale mode $(M=26.70, S D=25.92)$ was expected to be least effective when compared to time limit $(M=40.88, S D=29.61, p<.001)$ and self-monitoring $(M=45.21, S D=28.87, p<.001)$. The difference between the latter two was not significant $(p=.195)$. Before the smartphone project, participants expected self-monitoring to be the most effective and grayscale mode to be the least effective strategy for reducing screen time.

\section{Main Outcome: Screen Time}

The average daily screen time of our sample was 261.50 minutes ( $S D=91.34$ ). Table S2 shows the average daily screen time without collapsing over the screenshots. Since the project duration varied for the different master's programs due to scheduling constraints, participants submitted a varying number of screenshots $(M=2.33, S D=.84)$. Ninety-five percent of participants submitted screenshots for at least two weeks, $40 \%$ submitted screenshots for three weeks. The number of submitted screenshots did not differ across conditions $(F(2,109)=0.05, p=.953)$. 
A one-way ANOVA comparing the average screen time indicated a significant difference between conditions $(F(2,109)=3.30, p=0.040)$. Participants' average screen time in the passive nudge condition $(M=233.19, S D=88.18)$ was lower than in the control condition $(M=283.20, S D=97.25, t(77)=2.39$ $p=0.019)$. Participants' screen time in the passive nudge condition was also marginally lower than in the active nudge condition $(M=270.17, S D=81.10, t(71)=-1.84, p=0.068)$. There was no significant difference between the active nudge and control condition $(t(70)=0.61, p=0.543)$. This indicates that on average grayscale mode was effective in lowering participants' screen time by about 50 minutes per day. On average, screen time in the active nudge condition with time limits was not lower than in the control condition.

Next, we look at the progression over time without collapsing across data points using fixed-effects regression analysis. Figure 2 provides a graphical overview of the results over time across conditions. We regressed participants' average daily screen time on to the condition (base: control condition), the number of the submitted screenshot (week 1, week 2 etc.) as well as their interaction. Participants' screen time in the passive nudge condition did not vary over time (coefficient=-11.64, $p=0.152$ ). However, there was a significant interaction for the active nudge condition. Participants with self-imposed time limits significantly lowered their usage over time (coefficient=-20.37, $p=0.019$ ). This indicates that our grayscale intervention had an immediate and stable effect on screen time, while the time limits intervention helped people to gradually reduce their screen time.

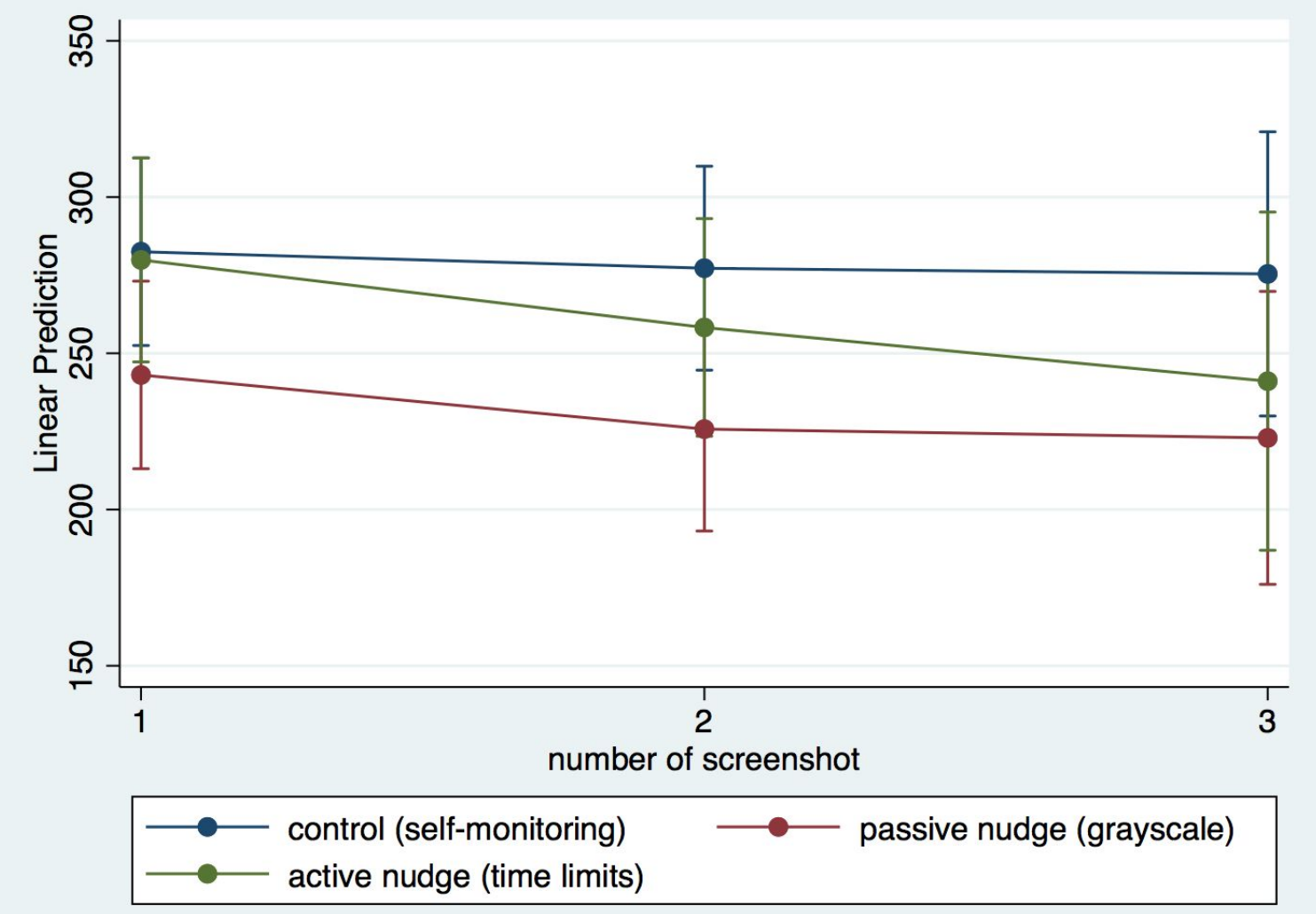

Figure 2. Screen time (in minutes) during the study period and across the experimental conditions. 


\section{Secondary Outcomes: Wellbeing and Performance}

\section{Subjective Well-being}

At baseline, there were no significant differences between conditions in terms of life satisfaction, stress level, sleep quality and happiness (all $p s=n s$ ). Importantly, after the intervention we also found no significant differences between the conditions for any of the wellbeing measures (all $p \mathrm{~s}=\mathrm{ns}$ ). Conducting repeated measure ANOVAS comparing pre- versus post-treatment effects for the different conditions, revealed no systematic patterns that would be consistent with the notion that a reduction of screen time improves well-being (see Table S3 for further details). We also created a general well-being index (see Table S4). However, we found no change over time or differences across conditions. Hence, reducing screen time did not have an immediate causal effect on subjective well-being.

\section{Academic Performance}

Students' GPA ( $M=3.56, S D=0.176)$ ranged from 3.17 to 4 , with higher scores indicating better academic performance. There were no significant GPA differences between conditions $(F(2,106)=0.10, p=0.905)$. However, we do find that students' average screen time significantly predicts GPA $(p=0.014)$. Every 30-minute decrease in screen time was associated with a 0.0135 increase in GPA. Controlling for age and gender did not impact the results.

\section{Acceptability and Feasibility}

Participants in the passive nudge condition indicated they had activated grayscale mode for approximately half the time during the intervention $(M=46.5, S D=32.79)$. Similarly, in the active nudge condition, participants indicated to have surpassed their self-set time limits about half the time $(M=$ $53.18, S D=29.70)$. While this data is not directly comparable, it indicates similar levels of acceptance. After the project, participants in the treatment conditions also evaluated the passive and active nudge as equally effective for reducing screen time (M_passive $=52.80, M$ active $=55.42, F(1,71)=0.12$, $p=0.732$ ).

In general, participants in the treatment conditions, especially in the active nudge condition ( $M=58.45)$, evaluated using the Screen Time app as more helpful for reducing mobile usage than participants in the control condition ( $M \_$passive $=51.10, M$ _control $=39.61, F(2,109)=4.05, p=0.020$ ). Further, participants in the treatment conditions, especially in the passive nudge condition $(M=57.62)$ felt more committed to reducing screen time than participants in the control condition ( $M_{-}$active $=55.90, M_{-}$control $=43.35, F(2$, 109) $=3.08, p=0$. 0.049). This indicates that both nudges positively influenced participants' perception of the Screen Time app and their ability to reduce usage.

\section{Other exploratory measures}

People with higher enjoyment ratings of social media tended to have a higher average screen time (coefficient=1.44, $p<0.001$ ). We do find that participants in the passive nudge condition enjoyed their social media time during the intervention marginally less than in the other conditions (coefficient=-9.27, $p=0.053$ ). This suggests that grayscale mode may have been effective in reducing screen time partially by lowering enjoyment of social media activities. Participants' estimated productive mobile time during the 
intervention, on the other hand, was not different across conditions. Finally, we found no differences across conditions regarding the attention measures (see Table S3 for descriptive and test statistics for all measures).

\section{Discussion}

We show that digital nudges can be effective tools to support people who wish to reduce their mobile usage. Our research highlights passive and active digital nudges that are available on nearly any smartphone and free of cost as effective solutions to mobile overuse. The passive nudge had an immediate and consistent effect on screen time. Participants who were encouraged to activate grayscale mode reduced their screen time by $17.6 \%$ compared to the control condition. On the other hand, the active nudge with time limits helped people to gradually reduce their screen time indicating habit formation. We suspect these results to be conservative estimates of the effectiveness since we did not enforce or incentivise compliance. Similar to past research (Okeke, Sobolev, Dell, et al., 2018), smartphone tracking alone, which constituted our control condition, in the absence of digital nudges did not lead to a change in mobile usage. It is becoming clear that self-monitoring is insufficient and that other solutions such as digital nudges are required to regulate phone usage.

Interestingly, participants' efficacy expectations showed exactly the opposite pattern to the empirical results. Participants believed self-monitoring to be most effective and grayscale mode to be least effective for reducing usage. This is in line with research showing that people typically prefer educative 'system 2' nudges that enhance powers of agency over non-educative 'system 1' nudges, unless they are informed about the effectiveness of the latter (Sunstein, 2016). Therefore, as a first step, it might be important to inform users which techniques really work and which don't for reducing usage.

We found no immediate causal effect of reducing screen time on subjective well-being and academic performance. While mobile technology influences the way we interact, connect and share information (David \& Roberts, 2017; Sherman et al., 2016), there seems to be little scientific evidence that well-being is generally harmed. Using self-reports, Przybylski and Weinstein (2017) found that moderate use of digital technology is not intrinsically harmful for adolescents and may even be advantageous. Similarly, Orben and Pryzbylski (2019b) found little evidence for negative associations between digital screen engagement and adolescent well-being. Hall et al. (2019) found that social media abstinence for four weeks had no effects on loneliness and wellbeing. We add experimental evidence to this growing literature that calls into question the popular narrative that screen time is harmful for well-being.

In line with previous research (Felisoni \& Godoi, 2018; Lepp et al., 2015), our results indicate that screen time is associated with academic performance. While screen time was linked to GPA, it is unclear whether students had lower grades because of the amount of time they spent on mobile, vice versa or due to other factors. Our digital nudges, however, did not lead to increased GPA despite lowering screen time. Technology multitasking whilst studying can have detrimental effects on performance (Ravizza et al., 2017). But recent evidence also suggests that the negative effect of smartphone use on academic performance may be overestimated (Bjerre-Nielsen et al., 2020). Our findings indicate that a general 
screen time reduction might not effectively translate into the desired increase in performance or productivity.

Our research approach and findings are of practical significance. In prior research, solutions of mobile overuse relied on applications that were specifically developed for research purposes (Allcott et al., 2020; Hiniker et al., 2016; Okeke, Sobolev, Dell, et al., 2018) which limits their scope. The advantage of using commercially developed screen time apps like we did in our study, is that they are available on the majority of smartphones. Hence, a large proportion of people have access to and can use these features easily. The use of digital nudges, as opposed to more costly interventions, could be applied ubiquitously and continuously (Okeke, Sobolev, \& Estrin, 2018) to self-regulate phone usage.

\section{Mechanisms and Future Research}

Our study tackles the relationship between phone usage and important life outcomes such as subjective well-being and performance. We find no evidence of a causal link, however this might depend on different measures of phone usage and outcomes. Screen time is composed of a variety of tasks that people undertake on their smartphones, ranging from meaningful to meaningless and from productive to problematic activities (Billieux et al., 2008; Lukoff et al., 2018; Panova \& Carbonell, 2018). Specific behaviors such as passive social media scrolling or phone checking at night might be especially problematic for sleep, well-being and performance (Liu et al., 2020). In the current study, data was collected via screenshots which limits our ability to conduct more nuanced analysis. Future research requires longitudinal data on different types of smartphone usage and more proximal daily outcomes.

Understanding the mechanisms behind the effect of digital nudges on screen time and related outcomes is of theoretical and practical significance. Our study was not designed or statistically powered to investigate mechanisms but we identified enjoyment of social media, which is considered most addictive and problematic (Ding et al., 2016), as a potential mechanism for the effect of the passive grayscale nudge. The gradual decline of screen time in the active nudge condition suggests that people progressively become better at achieving their self-set time limits. Future research should investigate general mechanisms for phone checking behavior and the effect of experience further (Roth et al., 2016).

\section{Conclusion}

Our research offers insights for researchers, practitioners and consumers who are interested in smartphone overuse and digital distraction. The findings can be used to encourage individuals, for example in workplace situations (Gill et al., 2012; Liu et al., 2020; Nevskaya \& Albuquerque, 2019) or in educational settings (David et al., 2015; Taneja et al., 2015), to use their smartphones less with the help of digital nudges. Considering that the median consumer would require a compensation of around $\$ 48$

to give up Facebook for one month (Brynjolfsson et al., 2019), there exists a consumer demand for cost-effective and scalable solutions to reduce mobile usage and screen time. 


\section{References}

Allcott, H., Braghieri, L., Eichmeyer, S., \& Gentzkow, M. (2020). The Welfare Effects of Social Media. American Economic Review, 110(3), 629-676. https://doi.org/10.1257/aer.20190658

Andrews, S., Ellis, D. A., Shaw, H., \& Piwek, L. (2015). Beyond Self-Report: Tools to Compare Estimated and Real-World Smartphone Use. PLOS ONE, 10(10), e0139004. https://doi.org/10.1371/journal.pone.0139004

Billieux, J., Van der Linden, M., \& Rochat, L. (2008). The role of impulsivity in actual and problematic use of the mobile phone. Applied Cognitive Psychology, 22(9), 1195-1210.

Bjerre-Nielsen, A., Andersen, A., Minor, K., \& Lassen, D. D. (2020). The Negative Effect of Smartphone Use on Academic Performance May Be Overestimated: Evidence From a 2-Year Panel Study. Psychological Science, 0956797620956613. https://doi.org/10.1177/0956797620956613

Boase, J., \& Ling, R. (2013). Measuring Mobile Phone Use: Self-Report versus Log Data. Journal of Computer-Mediated Communication, 18(4), 508-519. https://doi.org/10.1111/jcc4.12021

Brynjolfsson, E., Collis, A., \& Eggers, F. (2019). Using massive online choice experiments to measure changes in well-being. Proceedings of the National Academy of Sciences, 116(15), 7250-7255. https://doi.org/10.1073/pnas.1815663116

Cox, A. L., Gould, S. J. J., Cecchinato, M. E., lacovides, I., \& Renfree, I. (2016). Design Frictions for Mindful Interactions: The Case for Microboundaries. Proceedings of the $2016 \mathrm{CHI}$ Conference Extended Abstracts on Human Factors in Computing Systems, 1389-1397. https://doi.org/10.1145/2851581.2892410

David, M., \& Roberts, J. (2017). Phubbed and Alone: Phone Snubbing, Social Exclusion, and Attachment to Social Media. Journal of the Association for Consumer Research, 2(2), 155-163. https://doi.org/10.1086/690940

David, P., Kim, J.-H., Brickman, J. S., Ran, W., \& Curtis, C. M. (2015). Mobile phone distraction while 
studying. New Media \& Society, 17(10), 1661-1679.

https://doi.org/10.1177/1461444814531692

Ding, X., Xu, J., Chen, G., \& Xu, C. (2016). Beyond Smartphone Overuse: Identifying Addictive Mobile Apps. Proceedings of the $2016 \mathrm{CHI}$ Conference Extended Abstracts on Human Factors in Computing Systems, 2821-2828. https://doi.org/10.1145/2851581.2892415

Felisoni, D. D., \& Godoi, A. S. (2018). Cell phone usage and academic performance: An experiment. Computers \& Education, 117, 175-187. https://doi.org/10.1016/j.compedu.2017.10.006

Frederick, S. (2005). Cognitive Reflection and Decision Making. Journal of Economic Perspectives, 19(4), 25-42. https://doi.org/10.1257/089533005775196732

Gill, P. S., Kamath, A., \& Gill, T. S. (2012). Distraction: An assessment of smartphone usage in health care work settings. Risk Management and Healthcare Policy, 5, 105-114. https://doi.org/10.2147/RMHP.S34813

GlobalWebIndex. (2020). Social. GlobalWebIndex.

Gneezy, U., Meier, S., \& Rey-Biel, P. (2011). When and Why Incentives (Don't) Work to Modify Behavior. Journal of Economic Perspectives, 25(4), 191-210. https://doi.org/10.1257/jep.25.4.191

Gosling, S. D., Rentfrow, P. J., \& Swann, W. B. (2003). A very brief measure of the Big-Five personality domains. Journal of Research in Personality, 37(6), 504-528. https://doi.org/10.1016/S0092-6566(03)00046-1

Hall, J. A., Kearney, M. W., \& Xing, C. (2019). Two tests of social displacement through social media use. Information, Communication \& Society, 22(10), 1396-1413. https://doi.org/10.1080/1369118X.2018.1430162

Hiniker, A., Hong, S. (Ray), Kohno, T., \& Kientz, J. A. (2016). MyTime: Designing and Evaluating an Intervention for Smartphone Non-Use. Proceedings of the 2016 CHI Conference on Human Factors in Computing Systems, 4746-4757. https://doi.org/10.1145/2858036.2858403 
Kaye, L., Orben, A., A. Ellis, D., C. Hunter, S., \& Houghton, S. (2020). The Conceptual and Methodological Mayhem of "Screen Time." International Journal of Environmental Research and Public Health, 17(10), 3661. https://doi.org/10.3390/ijerph17103661

Lanaj, K., Johnson, R. E., \& Barnes, C. M. (2014). Beginning the workday yet already depleted? Consequences of late-night smartphone use and sleep. Organizational Behavior and Human Decision Processes, 124(1), 11-23. https://doi.org/10.1016/j.obhdp.2014.01.001

Lee, Y.-K., Chang, C.-T., Lin, Y., \& Cheng, Z.-H. (2014). The dark side of smartphone usage: Psychological traits, compulsive behavior and technostress. Computers in Human Behavior, 31, 373-383.

Lepp, A., Barkley, J. E., \& Karpinski, A. C. (2015). The Relationship Between Cell Phone Use and Academic Performance in a Sample of U.S. College Students: SAGE Open. https://doi.org/10.1177/2158244015573169

Liu, H., Ji, Y., \& Dust, S. B. (2020). "Fully recharged" evenings? The effect of evening cyber leisure on next-day vitality and performance through sleep quantity and quality, bedtime procrastination, and psychological detachment, and the moderating role of mindfulness. The Journal of Applied Psychology. https://doi.org/10.1037/apl0000818

Lukoff, K., Yu, C., Kientz, J., \& Hiniker, A. (2018). What Makes Smartphone Use Meaningful or Meaningless? Proceedings of the ACM on Interactive, Mobile, Wearable and Ubiquitous Technologies, 2(1), 22:1-22:26. https://doi.org/10.1145/3191754

Lyngs, U., Lukoff, K., Slovak, P., Binns, R., Slack, A., Inzlicht, M., Van Kleek, M., \& Shadbolt, N. (2019). Self-Control in Cyberspace: Applying Dual Systems Theory to a Review of Digital Self-Control Tools. Proceedings of the 2019 CHI Conference on Human Factors in Computing Systems, 1-18. https://doi.org/10.1145/3290605.3300361

Melumad, S., \& Pham, M. T. (2020). The Smartphone as a Pacifying Technology. Journal of Consumer Research, 47(2), 237-255. https://doi.org/10.1093/jcr/ucaa005 
Murnane, E. L., Huffaker, D., \& Kossinets, G. (2015). Mobile health apps: Adoption, adherence, and abandonment. Adjunct Proceedings of the 2015 ACM International Joint Conference on Pervasive and Ubiquitous Computing and Proceedings of the 2015 ACM International Symposium on Wearable Computers, 261-264. https://doi.org/10.1145/2800835.2800943

Nevskaya, Y., \& Albuquerque, P. (2019). How Should Firms Manage Excessive Product Use? A Continuous-Time Demand Model to Test Reward Schedules, Notifications, and Time Limits. Journal of Marketing Research, 56(3), 379-400. https://doi.org/10.1177/0022243718821698

Okeke, F., Sobolev, M., Dell, N., \& Estrin, D. (2018). Good Vibrations: Can a Digital Nudge Reduce Digital Overload? Proceedings of the 20th International Conference on Human-Computer Interaction with Mobile Devices and Services, 4:1-4:12. https://doi.org/10.1145/3229434.3229463

Okeke, F., Sobolev, M., \& Estrin, D. (2018). Towards A Framework for Mobile Behavior Change Research. Proceedings of the Technology, Mind, and Society, 27:1-27:6. https://doi.org/10.1145/3183654.3183706

Orben, A., \& Przybylski, A. K. (2019a). The association between adolescent well-being and digital technology use. Nature Human Behaviour, 3(2), 173-182. https://doi.org/10.1038/s41562-018-0506-1

Orben, A., \& Przybylski, A. K. (2019b). Screens, Teens, and Psychological Well-Being: Evidence From Three Time-Use-Diary Studies. Psychological Science, 30(5), 682-696. https://doi.org/10.1177/0956797619830329

Panova, T., \& Carbonell, X. (2018). Is smartphone addiction really an addiction? Journal of Behavioral Addictions, 7(2), 252-259. https://doi.org/10.1556/2006.7.2018.49

Przybylski, A. K., \& Weinstein, N. (2017). A Large-Scale Test of the Goldilocks Hypothesis: Quantifying the Relations Between Digital-Screen Use and the Mental Well-Being of Adolescents. Psychological Science, 28(2), 204-215. https://doi.org/10.1177/0956797616678438 
Ravizza, S. M., Uitvlugt, M. G., \& Fenn, K. M. (2017). Logged In and Zoned Out: How Laptop Internet Use Relates to Classroom Learning. Psychological Science, 28(2), 171-180. https://doi.org/10.1177/0956797616677314

Roth, Y., Wänke, M., \& Erev, I. (2016). Click or Skip: The Role of Experience in Easy-Click Checking Decisions. Journal of Consumer Research, 43(4), 583-597. https://doi.org/10.1093/jcr/ucw053 Sherman, L. E., Payton, A. A., Hernandez, L. M., Greenfield, P. M., \& Dapretto, M. (2016). The Power of the Like in Adolescence: Effects of Peer Influence on Neural and Behavioral Responses to Social Media. Psychological Science, 27(7), 1027-1035. https://doi.org/10.1177/0956797616645673

Sobolev, M., Vitale, R., Wen, H., Kizer, J., Leeman, R., Pollak, J. P., Baumel, A., Nehal P Vadhan, Estrin, D., \& Muench, F. (2020). Digital Marshmallow Test (DMT): Diagnostic and Monitoring mHealth App for Impulsive Behavior. JMIR Mhealth Uhealth. https://doi.org/10.2196/25018

Statista. (2020). Statista TrendCompass. Statista.

Sunstein, C. R. (2016). People prefer system 2 nudges (kind of). Duke LJ, 66, 121.

Taneja, A., Fiore, V., \& Fischer, B. (2015). Cyber-slacking in the classroom: Potential for digital distraction in the new age. Computers \& Education, 82, 141-151. https://doi.org/10.1016/j.compedu.2014.11.009

Thaler, R. H., \& Sunstein, C. R. (2008). Nudge: Improving Decisions about Health, Wealth, and Happiness. Yale University Press.

Thomée, S., Härenstam, A., \& Hagberg, M. (2011). Mobile phone use and stress, sleep disturbances, and symptoms of depression among young adults-A prospective cohort study. BMC Public Health, 11(1), 66. https://doi.org/10.1186/1471-2458-11-66

Ward, A. F., Duke, K., Gneezy, A., \& Bos, M. W. (2017). Brain Drain: The Mere Presence of One's Own Smartphone Reduces Available Cognitive Capacity. Journal of the Association for Consumer Research, 2(2), 140-154. https://doi.org/10.1086/691462 
Wen, H., Sobolev, M., Vitale, R., Kizer, J., Pollak, J. P., Estrin, D., \& Muench, F. (2020). mPulse: Passive Detection of Impulsive Behavior using Mobile Sensing. JMIR Ment Health. https://doi.org/10.2196/25019 


\section{Supplementary Material}

\section{Figure S1. CONSORT Diagram}

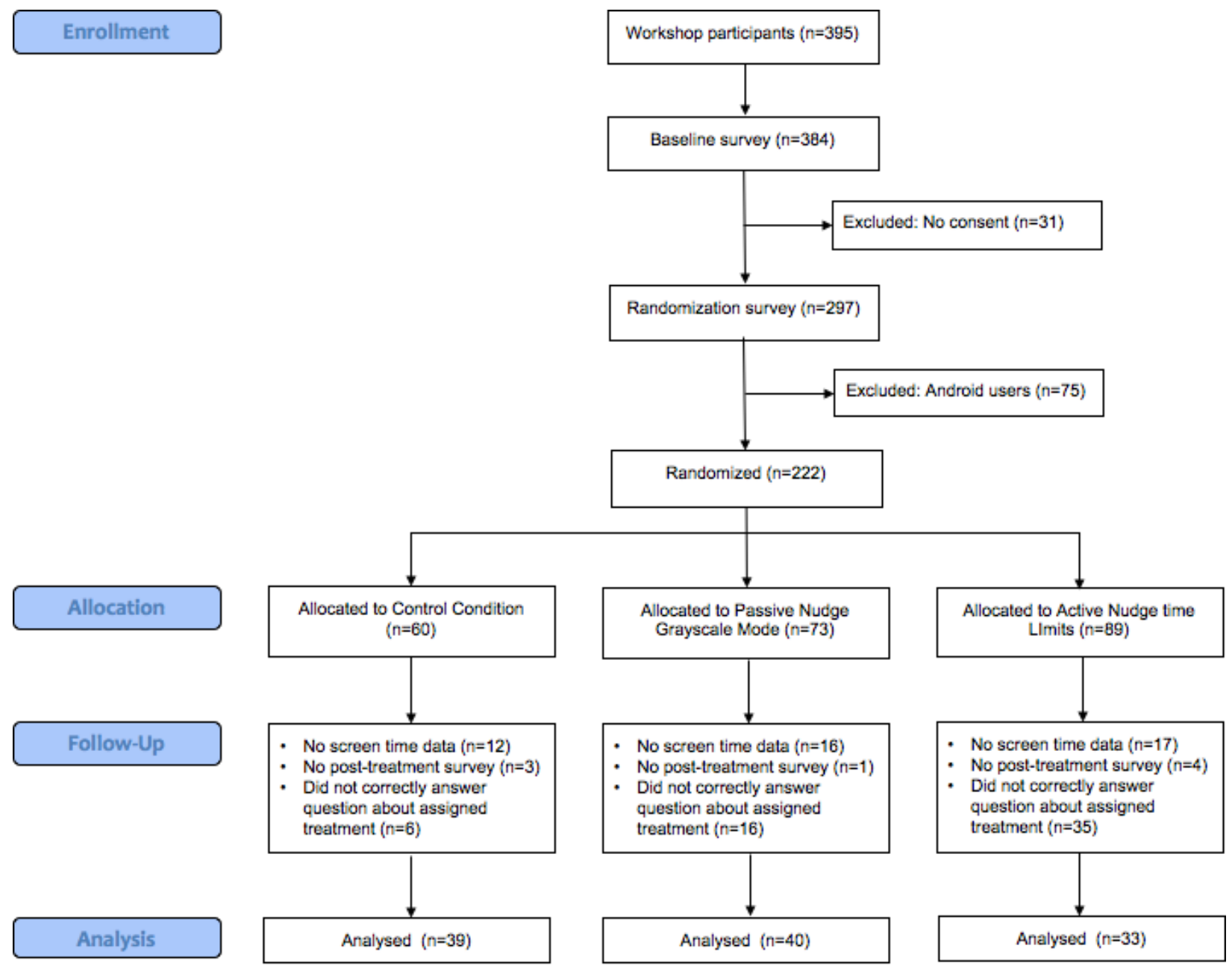


Table S1. Sample Characterization

\begin{tabular}{|c|c|c|c|c|c|}
\hline & $\begin{array}{c}\text { Total } \\
\text { sample }\end{array}$ & $\begin{array}{c}\text { Control } \\
\text { (Tracking } \\
\text { ) }\end{array}$ & $\begin{array}{c}\text { Passive } \\
\text { Nudge } \\
\text { (Grayscal } \\
\text { e) } \\
\end{array}$ & $\begin{array}{c}\text { Active } \\
\text { Nudge } \\
\text { (Time } \\
\text { Limits) }\end{array}$ & Test-statistic \\
\hline Sample size & 112 & 39 & 40 & 33 & \\
\hline \multicolumn{6}{|l|}{ Demographics } \\
\hline Age & $\begin{array}{l}25.58 \\
(3.62)\end{array}$ & $\begin{array}{l}26.61 \\
(4.28)\end{array}$ & $\begin{array}{l}24.97 \\
(2.69)\end{array}$ & $\begin{array}{l}25.09 \\
(3.56)\end{array}$ & $\begin{array}{c}F(2,108)=2.50 \\
p=0.08\end{array}$ \\
\hline Female \% & 77.06 & 76.92 & 71.79 & 83.87 & $\begin{array}{c}\operatorname{Chi2}(2)=1.42, \mathrm{p} \\
=0.49\end{array}$ \\
\hline \multicolumn{6}{|l|}{ Personality traits } \\
\hline Extraversion & $\begin{array}{c}9.33 \\
(2.78)\end{array}$ & $\begin{array}{c}9.27 \\
(2.60)\end{array}$ & $\begin{array}{c}9.57 \\
(3.07)\end{array}$ & $\begin{array}{c}9.12 \\
(2.65)\end{array}$ & $\begin{array}{c}F(2,106)=0.25 \\
p=0.77\end{array}$ \\
\hline Conscientiousness & $\begin{array}{c}10.9 \\
(2.21)\end{array}$ & $\begin{array}{l}11.11 \\
(1.92)\end{array}$ & $\begin{array}{c}10.3 \\
(2.78)\end{array}$ & $\begin{array}{l}11.42 \\
(1.50)\end{array}$ & $\begin{array}{c}F(2,105)=2.63 \\
p=0.07\end{array}$ \\
\hline Agreeableness & $\begin{array}{c}9.28 \\
(1.81)\end{array}$ & $\begin{array}{c}9.4 \\
(1.88)\end{array}$ & $\begin{array}{c}9.25 \\
(1.49)\end{array}$ & $\begin{array}{c}9.21 \\
(2.13)\end{array}$ & $\begin{array}{c}F(2,104)=0.10 \\
p=0.90\end{array}$ \\
\hline Emotional stability & $\begin{array}{c}9.13 \\
(2.51)\end{array}$ & $\begin{array}{c}9.58 \\
(2.41)\end{array}$ & $\begin{array}{c}8.8 \\
(2.68)\end{array}$ & $\begin{array}{c}9.06 \\
(2.39)\end{array}$ & $\begin{array}{c}F(2,106)=0.94 \\
p=0.39\end{array}$ \\
\hline Openness & $\begin{array}{l}11.27 \\
(1.66)\end{array}$ & $\begin{array}{l}11.66 \\
(1.62)\end{array}$ & $\begin{array}{l}10.87 \\
(1.93)\end{array}$ & $\begin{array}{l}11.33 \\
(1.21)\end{array}$ & $\begin{array}{c}F(2,106)=2.23 \\
p=0.11\end{array}$ \\
\hline \multicolumn{6}{|l|}{ Phone behavior T1 } \\
\hline Prior use of tracking app (\% yes) & 54.05 & 51.28 & 56.41 & 54.55 & $\begin{array}{c}\text { Chi2(4) }=3.29, p \\
=0.50\end{array}$ \\
\hline Estimated screen time daily minutes & $\begin{array}{c}221.1 \\
(102.86)\end{array}$ & $\begin{array}{l}210.61 \\
(85.74)\end{array}$ & $\begin{array}{l}206.66 \\
(98.29)\end{array}$ & $\begin{array}{c}250.57 \\
(122.00)\end{array}$ & $\begin{array}{c}F(2,108)=1.98 \\
p=0.14\end{array}$ \\
\hline Estimated number of notifications & $\begin{array}{c}106.78 \\
(117.41)\end{array}$ & $\begin{array}{c}97.68 \\
(89.85)\end{array}$ & $\begin{array}{c}105.82 \\
(118.39)\end{array}$ & $\begin{array}{c}118.39 \\
(144.03)\end{array}$ & $\begin{array}{c}F(2,107)=0.27 \\
p=0.76\end{array}$ \\
\hline Estimated number of unlocks & $\begin{array}{c}69.11 \\
(56.25)\end{array}$ & $\begin{array}{c}63.02 \\
(51.87)\end{array}$ & $\begin{array}{c}70.94 \\
(61.96)\end{array}$ & $\begin{array}{c}74.15 \\
(55.20)\end{array}$ & $\begin{array}{c}F(2,108)=0.38 \\
p=0.68\end{array}$ \\
\hline $\begin{array}{l}\text { How much could you reduce screen time } \\
(0-100 \%)\end{array}$ & $\begin{array}{c}52.61 \\
(18.75)\end{array}$ & $\begin{array}{c}51.15 \\
(21.35)\end{array}$ & $\begin{array}{c}53 \\
(17.05)\end{array}$ & $\begin{array}{c}53.87 \\
(17.82)\end{array}$ & $\begin{array}{c}F(2,108)=0.20 \\
p=0.82\end{array}$ \\
\hline Smartphone dependence & $\begin{array}{c}3.97 \\
(1.16)\end{array}$ & $\begin{array}{c}4.1 \\
(1.32)\end{array}$ & $\begin{array}{c}4.01 \\
(1.01)\end{array}$ & $\begin{array}{c}3.79 \\
(1.15)\end{array}$ & $\begin{array}{c}F(2,108)=0.64 \\
p=0.52\end{array}$ \\
\hline \multicolumn{6}{|l|}{ Efficacy expectations } \\
\hline $\begin{array}{l}\text { Looking at detailed information about } \\
\text { your individual mobile phone usage }\end{array}$ & $\begin{array}{r}45.21 \\
(28.87)\end{array}$ & $\begin{array}{c}43.38 \\
(28.87)\end{array}$ & $\begin{array}{c}43.56 \\
(28.05)\end{array}$ & $\begin{array}{c}49.33 \\
(30.27)\end{array}$ & $\begin{array}{c}F(2,108)=0.47 \\
p=0.62\end{array}$ \\
\hline $\begin{array}{l}\text { Setting yourself time limits for different } \\
\text { apps }\end{array}$ & $\begin{array}{c}40.88 \\
(29.61)\end{array}$ & $\begin{array}{c}39.82 \\
(29.83)\end{array}$ & $\begin{array}{c}39.82 \\
(27.86)\end{array}$ & $\begin{array}{c}43.39 \\
(32.04)\end{array}$ & $\begin{array}{c}F(2,108)=0.17 \\
p=0.84\end{array}$ \\
\hline $\begin{array}{l}\text { Turning your mobile phone to grayscale } \\
\text { mode (screen in black and white) }\end{array}$ & $\begin{array}{c}26.70 \\
(25.92) \\
\end{array}$ & $\begin{array}{r}29.07 \\
(27.68) \\
\end{array}$ & $\begin{array}{r}23.25 \\
(26.08) \\
\end{array}$ & $\begin{array}{r}27.96 \\
(23.85) \\
\end{array}$ & $\begin{array}{c}F(2,108)=0.54 \\
p=0.58\end{array}$ \\
\hline
\end{tabular}


Table S2. Screenshots Data

\begin{tabular}{lccc}
\hline & $\mathrm{N}$ & $\mathrm{M}$ & $\mathrm{SD}$ \\
\hline Screenshot 1 & 112 & 267.36 & 98.24 \\
Screenshot 2 & 95 & 254.84 & 95.96 \\
Screenshot 3 & 45 & 246.46 & 90.65 \\
Average screen time & 112 & 261.50 & 91.34 \\
\hline
\end{tabular}

Table S3. Results for T1 and T2 survey measures across conditions

\begin{tabular}{|c|c|c|c|c|c|c|c|c|c|c|}
\hline & & & T1 Base & ine & & & & Post-Tre & atment & \\
\hline & Total & Control & $\begin{array}{l}\text { Passive } \\
\text { Nudge }\end{array}$ & $\begin{array}{l}\text { Active } \\
\text { Nudge }\end{array}$ & $\begin{array}{c}\text { Test- } \\
\text { statistic }\end{array}$ & Total & Control & $\begin{array}{l}\text { Passive } \\
\text { Nudge }\end{array}$ & $\begin{array}{l}\text { Active } \\
\text { Nudge }\end{array}$ & $\begin{array}{c}\text { Test- } \\
\text { statistic }\end{array}$ \\
\hline Life satisfaction & $\begin{array}{r}75.28 \\
(15.60)\end{array}$ & $\begin{array}{c}75.64 \\
(13.56)\end{array}$ & $\begin{array}{c}73.30 \\
(19.61)\end{array}$ & $\begin{array}{c}77.21 \\
(12.36)\end{array}$ & $\begin{array}{c}F(2, \\
108)=0.57, \\
p=.567\end{array}$ & $\begin{array}{c}78.25 \\
(17.14)\end{array}$ & $\begin{array}{c}80.15 \\
(16.45)\end{array}$ & $\begin{array}{c}78.65 \\
(19.24)\end{array}$ & $\begin{array}{c}75.51 \\
(15.28)\end{array}$ & $\begin{array}{c}F(2, \\
109)=0.67, \\
p=.515\end{array}$ \\
\hline Stress level & $\begin{array}{c}46.64 \\
(27.56)\end{array}$ & $\begin{array}{l}46.20 \\
(26.76)\end{array}$ & $\begin{array}{c}46.94 \\
(30.93)\end{array}$ & $\begin{array}{c}46.81 \\
(24.98)\end{array}$ & $\begin{array}{c}F(2, \\
108)=0.01, \\
p=.992\end{array}$ & $\begin{array}{c}51.34 \\
(24.84)\end{array}$ & $\begin{array}{c}49.05 \\
(22.58)\end{array}$ & $\begin{array}{c}52.12 \\
(27.34)\end{array}$ & $\begin{array}{c}53.12 \\
(24.76)\end{array}$ & $\begin{array}{c}F(2, \\
109)=0.27, \\
p=.766\end{array}$ \\
\hline Sleep quality & $\begin{array}{r}68.86 \\
(26.28)\end{array}$ & $\begin{array}{l}70.28 \\
(24.30)\end{array}$ & $\begin{array}{c}67.84 \\
(30.26)\end{array}$ & $\begin{array}{c}68.39 \\
(24.10)\end{array}$ & $\begin{array}{c}F(2, \\
108)=0.09, \\
p=.914\end{array}$ & $\begin{array}{c}66.47 \\
(26.38)\end{array}$ & $\begin{array}{r}68.30 \\
(25.54)\end{array}$ & $\begin{array}{l}64.45 \\
(27.78)\end{array}$ & $\begin{array}{c}66.75 \\
(26.26)\end{array}$ & $\begin{array}{c}F(2, \\
109)=0.21, \\
p=.810\end{array}$ \\
\hline Happiness & $\begin{array}{l}2.40 \\
(0.56)\end{array}$ & $\begin{array}{l}2.43 \\
(0.59)\end{array}$ & $\begin{array}{r}2.41 \\
(0.59)\end{array}$ & $\begin{array}{l}2.36 \\
(0.48)\end{array}$ & $\begin{array}{c}F(2, \\
108)=0.15, \\
p=.862\end{array}$ & $\begin{array}{c}2.52 \\
(0.55)\end{array}$ & $\begin{array}{r}2.48 \\
(0.60)\end{array}$ & $\begin{array}{r}2.60 \\
(0.49)\end{array}$ & $\begin{array}{c}2.48 \\
(0.56)\end{array}$ & $\begin{array}{c}F(2, \\
109)=0.54, \\
p=.583\end{array}$ \\
\hline $\begin{array}{l}\text { General Wellbeing } \\
\text { Index }\end{array}$ & $\begin{array}{c}0.02 \\
(0.82)\end{array}$ & $\begin{array}{c}0.06 \\
(0.78)\end{array}$ & $\begin{array}{l}-0.02 \\
(0.97)\end{array}$ & $\begin{array}{l}0.03 \\
(0.70)\end{array}$ & $\begin{array}{c}F(2, \\
108)=0.11, \\
p=.893\end{array}$ & $\begin{array}{c}0.06 \\
(0.87)\end{array}$ & $\begin{array}{l}0.11 \\
(0.88)\end{array}$ & $\begin{array}{l}0.11 \\
(0.90)\end{array}$ & $\begin{array}{l}-0.03 \\
(0.83)\end{array}$ & $\begin{array}{c}F(2, \\
109)=0.32, \\
p=.729\end{array}$ \\
\hline Cognitive Reflection & - & - & - & - & - & $\begin{array}{c}1.43 \\
(1.22)\end{array}$ & $\begin{array}{l}1.40 \\
(1.28)\end{array}$ & $\begin{array}{l}1.42 \\
(1.15)\end{array}$ & $\begin{array}{c}1.5 \\
(1.27)\end{array}$ & $\begin{array}{c}F(2, \\
102)=0.06, \\
p=.941\end{array}$ \\
\hline
\end{tabular}




\begin{tabular}{|c|c|c|c|c|c|c|c|c|c|c|}
\hline $\begin{array}{l}\text { Attention filter (\% } \\
\text { detected) }\end{array}$ & - & - & - & - & - & 88.79 & 94.29 & 87.5 & 84.38 & $\begin{array}{c}\operatorname{chi} 2(2)=1.7 \\
5, p=.416\end{array}$ \\
\hline $\begin{array}{l}\text { Social media } \\
\text { enjoyment }\end{array}$ & - & - & - & - & - & $\begin{array}{c}52.28 \\
(24.30)\end{array}$ & $\begin{array}{c}55.17 \\
(26.47)\end{array}$ & $\begin{array}{c}46.32 \\
(26.45)\end{array}$ & $\begin{array}{c}56.09 \\
(17.15)\end{array}$ & $\begin{array}{c}F(2, \\
111)=1.92, \\
p=.152\end{array}$ \\
\hline $\begin{array}{l}\% \text { of productive } \\
\text { mobile usage }\end{array}$ & - & - & - & - & - & $\begin{array}{c}45.36 \\
(18.36)\end{array}$ & $\begin{array}{c}41.79 \\
(16.84)\end{array}$ & $\begin{array}{c}47.97 \\
(20.53)\end{array}$ & $\begin{array}{c}46.42 \\
(17.15)\end{array}$ & $\begin{array}{c}F(2, \\
109)=1.20, \\
p=.305\end{array}$ \\
\hline $\begin{array}{l}\text { Was the app helpful } \\
\text { to reduce usage? }\end{array}$ & - & - & - & - & - & $\begin{array}{c}49.26 \\
(29.20)\end{array}$ & $\begin{array}{c}39.61 \\
(26.23)\end{array}$ & $\begin{array}{c}51.10 \\
(29.72)\end{array}$ & $\begin{array}{c}58.45 \\
(29.31)\end{array}$ & $\begin{array}{c}F(2, \\
109)=4.05, \\
p=.020\end{array}$ \\
\hline $\begin{array}{l}\text { Feeling committed to } \\
\text { reduce usage? }\end{array}$ & - & - & - & - & - & $\begin{array}{c}52.15 \\
(28.06)\end{array}$ & $\begin{array}{c}43.35 \\
(25.82)\end{array}$ & $\begin{array}{c}57.62 \\
(29.70)\end{array}$ & $\begin{array}{c}55.90 \\
(26.79)\end{array}$ & $\begin{array}{c}F(2, \\
109)=3.08, \\
p=.049\end{array}$ \\
\hline
\end{tabular}

Table S4. General wellbeing index factor analysis

\begin{tabular}{lcccc}
\hline & \multicolumn{2}{c}{ T1 Baseline } & T2 Post-Treatment \\
& Factor 1 & Uniqueness & Factor 1 & Uniqueness \\
& & & & \\
\hline Life satisfaction & 0.70 & 0.50 & 0.77 & 0.39 \\
Stress level & 0.56 & 0.67 & 0.50 & 0.74 \\
Sleep quality & -0.65 & 0.56 & -0.53 & 0.71 \\
Happiness & 0.67 & 0.54 & 0.74 & 0.43
\end{tabular}

